Max-Planck-Institut für demografische Forschung

Max Planck Institute for Demographic Research

Konrad-Zuse-Strasse 1 - D-18057 Rostock - GERMANY

Tel +49 (0) 3812081 - 0; Fax +49 (0) 3812081 - 202;

http://www.demogr.mpg.de

MPIDR WORKING PAPER WP 2011-018

NOVEMBER 2011

\title{
Urban Fertility Responses \\ to Local Government Programs: \\ Evidence from the 1923-1932 U.S.
}

Jonathan Fox (jfox@demogr.mpg.de)

Mikko Myrskylä (myrskyla@demogr.mpg.de)

(C) Copyright is held by the authors.

Working papers of the Max Planck Institute for Demographic Research receive only limited review. Views or opinions expressed in working papers are attributable to the authors and do not necessarily reflect those of the Institute. 


\title{
Urban Fertility Responses to Local Government Programs: Evidence from the 1923-1932 U.S.
}

\author{
Jonathan Fox ${ }^{1}$ \\ Max Planck Institute for Demographic Research
}

\author{
Mikko Myrskylä \\ Max Planck Institute for Demographic Research
}

\section{October 2011}

\begin{abstract}
During the 1920s and early 1930s, fertility in American municipalities declined overall and with large variation between areas and across time. Using data for 1923-1932 on fertility and public spending for over 50 large cities, we show that the local government programs of health education and outdoor care of poor had the unintended effect of reducing fertility. Fixed effects regressions indicate a $\$ 4$ increase in per capita public health education spending or a $\$ 37$ increase in poor relief reduced the TFR by 0.1 . This suggests that cities spending in the $75^{\text {th }}$ percentile on health education experienced a $1.95 \%$ faster fertility decline than cities spending in the $25^{\text {th }}$ percentile. For poor relief the difference was $1.45 \%$. The mechanisms may be related to increased breastfeeding, social insurance incentives or the stressing of a two child home. The results help explain differing fertility trends, and highlight how policy may unintentionally reduce fertility.
\end{abstract}

\footnotetext{
${ }^{1}$ Contact Author: Jonathan Fox, jfox@demogr.mpg.de. Max Planck Institute for Demographic Research, Konrad-Zuse-Strasse 1, 18057 Rostock, Germany. +49 (0)381 2081-192. We wish to thank Michael Haines, Martha Bailey, Price Fishback, Tommy Bengtsson, Maria Stanfors and J. David Hacker, as well as seminar participants at the Lund University Centre for Economic Demography for helpful comments and suggestions. Preliminary draft; please do not quote or cite without permission.
} 


\section{Introduction}

This paper investigates the declining fertility in American cities in the decade preceding the New Deal and examines whether the declines were partly due to unintended effects from municipal level public health education and poverty relief programs. During the 1920s and early 1930s, fertility in large U.S. urban areas was trending downward, with the Total Fertility Rate dipping below 2 for the first time. While there were no specific public programs targeting fertility, public health education programs which were implemented with the goal of improving health outcomes may have unintentionally helped contribute to these low fertility outcomes across cities. Additionally, charitable programs were implemented across the municipalities as a way to alleviate some of the harmful effects of poverty and may have also placed downward pressure on fertility. We examine to what extent differences in investment in these two types of programs explains differences in fertility outcomes across a set of large urban areas in the United States.

Urban and rural fertility in the United States was declining as early as the pre-civil war period (Haines 2000), a phenomenon generally attributed to changing demographic, religious or economic circumstances. These same factors were very likely also partly responsible for the differences in fertility trends and levels for U.S. cities during the 1920s. This paper does not attempt a full explanation of the early twentieth century urban fertility story, but instead examines the impact on municipal fertility from a single factor, the investment in different public programs, which has thus far been neglected but is important. Understanding this relationship is important both from an historical perspective as well as for informing current policy. If these programs affected fertility in U.S. cities, they potentially offer a tool for governments looking to lower their own fertility. It is unlikely the public health programs were 
implemented with the intent of lowering fertility within the different cities, however, leaders of the educational programs advocated the importance of birth spacing and smaller families for improvements in child health outcomes (Woodbury 1925, Lathrop 1919). A relationship between these public health education programs and fertility will indicate individuals altered their behavior in response to the programs and that lower fertility resulted. Additionally, it is important to remember that public programs may affect individual behavior even when those effects are unintended. These public health education programs were implemented in a period of distress over falling birth rates and calls for improving the stock as well as the quality of the population (Hoffmann 1909, Newsholme and Stevenson 1906, Willcox 1911, Newmayer 1911, Meckel 1990: pp 102). Given this, it is likely support for the public health education programs contained an element of increasing the U.S. population. Organizations looking to implement these types of programs to improve health or economic outcomes should be aware of any potential unintended effects.

Determining whether these programs affected fertility will shed light not only on why fertility rates were declining steadily prior to the Great Depression, but also why fertility outcomes differed so much across cities in the United States. Variation in fertility across areas has been a constant feature of the United States, and continues to be the case today (U.S. Bureau of the Census 2011: Section 2, Table 82). Understanding how different levels of investment in different types of public policies can effect changes in fertility helps illustrate how conscious policy can cause outcomes to differ across areas.

Despite the common perception that the Great Depression drove down fertility rates across the U.S., within large American municipalities most of the action in declining fertility occurred prior to 1930 . For U.S. cities over 100,000 persons in 
1920 that were also a part of the Birth Registration Area, over 80 percent of the fertility decline between 1920 and 1940 occurred in those first 10 years. Birth rates in these cities were over 90 births per 1,000 women of childbearing age (women between the ages of 15 and 44) in 1920, declined to just over 70 births per 1,000 women of childbearing age in 1930 and fell to just over 66 births per 1,000 women of childbearing age in 1940. Scaled for comparison with the widely used Total Fertility Rate, these numbers are analogous to a value of about 2.72 in 1920, 2.11 in 1930 and 1.99 in $1940 .^{2}$

These aggregated declines mask additional variation in municipal fertility outcomes. It is common to compare urban and rural fertility rates, especially during periods when urban and rural are synonymous with industrial and agricultural. However, this ignores the wide variation in fertility rates across urban areas in the U.S. during the first few decades of the 1900s. Strikingly, some cities hit total fertility rates below 1.5 as early as 1929, while others experienced fertility rates over 3 for the entirety of the decade. But before we can determine precisely how fertility changed and varied across areas, we must first decide how it is to be measured from imperfect historical data sources.

\section{Measuring Local Fertility with Historical U.S. Data}

Annual period fertility across and between municipalities is generally measured using the Total Fertility Rate (TFR). The TFR has an easy interpretation in that it represents the average number of children a woman would bear if she experienced the prevailing

\footnotetext{
${ }^{2}$ To scale the General Fertility Rate (number of births per woman of childbearing age times 1,000) so that it is comparable to the Total Fertility Rate, divide the General Fertility Rate by 1,000 and multiply by product of 6 (the number of five-year age groups for women between the ages of 15 and 44) and 5 (the length of the age group). If the childbearing population were assumed to be between the ages of 15 and 49, then it would be necessary to multiply by the product of 7 (for the additional five-year age group) and 5.
} 
age-specific fertility rates and survived through the end of her reproductive period. With no mortality before the end of the reproductive period, a TFR slightly greater than 2 (to account for a slightly greater frequency of male births) would correspond to the replacement level fertility where women on average replace themselves with one daughter. In the United States in the 1930s, the replacement level fertility was approximately $2.3^{3}$

To calculate the total fertility rate annually for each municipality, city-level information is required on the number of births, female population by age and the distribution of births by age of the mother. City birth counts are available annually for cities in the Birth Registration Area, but female population by age is only given in the Decennial Censuses and the distribution of births by age of the mother is only available at the state level. Given these limitations, we estimate the total fertility rate for each city using interpolated values of female population counts by age cohort and assume age-specific fertility rates in the municipalities are equivalent to those of the state in which the city resides. ${ }^{4}$ We name this estimated version of the total fertility rate $\mathrm{TFR}^{*}$ and use it in the model described in Section 5. As a robustness check, we have also estimated the model in Section 5 using the General Fertility Rate, and the conclusions remained the same.

Studies of U.S. fertility series prior to 1940 have generally avoided the issue of calculating age-specific fertility rates by either estimating the General Fertility Rate (Fishback et al 2007), by looking at the completed birth histories of women (Haines and Guest 2008, Jones and Tertilt 2006, David and Sanderson 1987) or simply by

\footnotetext{
${ }^{3}$ The replacement level fertility is approximated by $(1+\mathrm{SRB}) / \mathrm{p}(\mathrm{Am})$ where SRB is the sex ratio at birth and $\mathrm{p}(\mathrm{Am})$ is the probability of surviving to the mean age at childbearing. The replacement level fertility of 2.3 for the U.S. is calculated with $\mathrm{SRB}=1.04$ and $\mathrm{p}(\mathrm{Am})=0.88$. 0.88 was the lifetable probability of a newborn girl surviving to age 30 in year 1933 (Source: Human Mortality Database). ${ }^{4}$ Data entry of births by age of mother by state has not yet been completed, so for this version of the paper we use a national level fertility schedule (year 1933) as the benchmark when distributing fertility over age.
} 
studying child/woman ratios (U.S. Bureau of the Census 1975: Series B, pp 67-98). The General Fertility Rate, or GFR, is the ratio of births to the total number of women of childbearing age in an area. Since the GFR does not take age structure into account, differences in GFR over time or region may be attributable to differences in fertility or population structure. Birth histories, in turn, summarize information on completed fertility over the whole reproductive period spanning more than 30 years, and are therefore of limited use for studies of short term variation. Using TFR* allows exploitation of annual variation in fertility as well as the ability to control for differences in age structure across space and time. And as the total fertility rate is the most widely used measure of fertility, interpretation of the results in terms changes in TFR* is straightforward. ${ }^{5}$

\section{U.S. Fertility Prior to the Great Depression}

For those areas part of the Birth Registration Area (BRA), fertility not only fell fairly consistently during the 1920s and early 1930s, but also exhibited substantial variation between areas. By 1920, 60 percent of the states in the U.S. constituted the BRA. The area grew during the 1920s, whereby in 192844 states were officially recording births. Figure 1 maps the BRA states in 1923 and 1928 as well as the corresponding sample cities (cities over 100,000 persons in 1920). In the early 1920s, the Southeast and Central United States were largely underrepresented in the BRA, however by 1928 only New Mexico, Nevada, South Dakota and Texas chose not to participate. Plotting fertility for these areas in the 1920s, Figure 2 gives the TFR* in each year for the set 1921 BRA sample cities. With the exception of a brief increase in 1923 and 1924, average fertility across this set of cities fell consistently between

\footnotetext{
${ }^{5}$ The trends and even annual changes are very similar between TFR* and the GFR, so the conclusions regarding fertility changes should not depend on which tricks were used to calculate TFR*
} 
1921 and 1932. The rates of decline, however, varied between cities. Figure 2 plots fertility data individually for each of these cities, as well as the average level of fertility in each year across those cities. The average level of TFR* is indicated by a thick black line, and the cities with the highest and lowest fertility in 1923 (Fall River, MA; Camden, NJ; San Francisco CA; Seattle, WA) are labeled. Replacement level fertility, in this case 2.3, is indicated by the shaded area.

With few exceptions, fertility rates in the largest American municipalities declined through the 1920s and early 1930s. However, the paths differed substantially across areas. We illustrate this variation using two examples. The first compares the two cities with the highest fertility rates in 1923, Fall River, MA and Camden, NJ. Although Camden, NJ and Fall River, MA started at similar positions in the early 1920s, their fertility outcomes at the end were very different. Aside from a slight increase in 1932, fertility in Fall River declined monotonically between 1923 and 1932 from almost 4 children per woman to below the replacement level of 2.3 children per woman. The story differed in Camden, NJ where fertility fluctuated above 3 children per woman with no clear trend over the study period. Fertility in Camden increased slightly between 1923 and 1924, decreased in 1925 and again in 1926, rose in 1927 before it fell again during the next two years and then alternated between increasing and decreasing in 1930, 1931, and 1932. Although Camden, NJ and Fall River, MA started at similar positions in the early 1920s, their fertility outcomes at the end were very different. This variation is further illustrated with the second example comparing cities at the bottom of the fertility distribution in 1923, San Francisco, CA and Seattle, WA. While fertility rates in San Francisco decreased fairly consistently throughout the 1920s and early 1930s, fertility rates in Seattle remained fairly constant. Remarkably, San Francisco, CA, Los Angeles, CA, 
Portland, OR, and Kansas City, MO all had fertility rates below 1.5 by 1932 . It was San Francisco that hit this threshold as early as 1929.

Fertility was declining rapidly across most American municipalities during the 1920s and early 1930s as American urban areas underwent the transition from mostly above to mostly below replacement fertility (figures 1 and 2). This occurred during a period of generally stable economic conditions across the cities and with high income relative to the previous two decades. There was also substantial variation in both the fertility levels and trends across areas. Although fertility generally declined across the set of cities, some areas experienced much more rapid declines than others. Even within the same geographic area the trends differed. Camden, NJ and Philadelphia, PA are located on opposite sides of the same river, yet fertility in Philadelphia fell by over 30 percent between 1921 and 1932 while fertility in Camden dropped by 10 percent over the same period. In some cases, these differences between cities rivaled that of the urban/rural fertility difference. 1920 fertility in Fall River, MA was nearly 70 percent higher than fertility in San Francisco during that year. Looking at child/woman ratios, in 1920 the rural child/woman ratio was 58 percent greater than the urban child/woman ratio (Haines 2000). Based on rural birth counts of 745,665 and estimates of the rural female population between the ages of 15 and 44 of about 6.9 million, the General Fertility Rate in U.S. rural areas was just over 3.2. ${ }^{6}$ Five cities (New Bedford, MA (3.2), Bridgeport, CT (3.27), Hartford CT (3.29), Youngstown, $\mathrm{OH}(3.48)$ and Fall River, MA (3.49)) had fertility rates that exceeded this level during this year.

\footnotetext{
${ }^{6}$ Rural birth counts were obtained from the 1920 Birth Statistics for the Birth Registration Area. Estimates of the rural female population between 15 and 44 were calculated for each state in the Birth Registration Area by multiplying the ratio of women between the ages of 15 and 44 by the total female population located in that states' rural areas. Population counts by age and the gender distribution by urban and rural areas for each state were obtained from the 1920 U.S. Census.
} 


\subsection{Historical Declines of American Fertility and the Research Describing Them}

Economists, demographers and other social scientists have offered numerous explanations for why fertility in the United States fell in the $19^{\text {th }}$ and $20^{\text {th }}$ centuries. Not surprisingly, major differences exist among opinions regarding both the timing and the causes of U.S. fertility decline. Most research on the subject has dated the beginning of American fertility decline to the start of the $19^{\text {th }}$ century (Hirschman 1994, David and Sanderson 1987). However more recent research has argued that U.S. fertility did not decline until 1840 and that declines in marital fertility across the nation did not begin until the post-civil war period (Hacker 2003). Fertility then generally declined within the U.S. until the baby boom of the 1940s and 1950s (Jones and Tertilt 2007).

The causes of the U.S. fertility decline typically fit into the categories of changing behaviors, culture or values, a changing population structure, or a response to economic incentives. David and Sanderson (1987) argue that U.S. fertility declined between the mid- $19^{\text {th }}$ and mid- $20^{\text {th }}$ centuries partially due to the emergence of a two child norm and a growing prevalence of fertility control among married women. Using the number of children-ever-born, they attribute over half the decline in fertility between the 1855-1859 and 1910-1914 cohorts to reductions in fertility among women who used some form of birth control. This conclusion is based on estimating the number of women who actively controlled their fertility using Cohort Parity Analysis. Cohort Parity Analysis has since been criticized on methodological grounds (Okun 1994), so there is some question whether active efforts to control births accounted for such a large proportion of the fertility decline during this period.

Likewise, the effect of income on fertility has a long history in the fertility theory literature. It is generally believed that wages and fertility are negatively 
related, as increases in income cause individuals to reduce their fertility in favor of increasing investment per child (Becker and Tomes 1976). Using individual-level data on the number of children-ever-born for cohorts between 1826 and 1960, Jones and Tertilt (2006) confirm this negative relationship. The authors remain agnostic regarding the specific mechanism causing the relationship, but estimate that income as measured by occupation explains as much as 90 percent of differences in fertility across time and between groups.

Related to increases in income are reductions in mortality, specifically child and infant mortality. However, research on the effect of mortality on fertility is largely absent in much of the empirical literature (Mason 1997). However, many theoretical papers argued it can affect fertility in a number of ways. If individuals have a parity target (the total number of children born to them) then reducing mortality will reduce the need for both "hoarding” children (Sah 1991) as well as for replacement (Eckstein et. al. 1999, Doepke 2005). Additionally, reducing infant and child mortality reduces the expected cost of raising a surviving child (Barro and Becker 1989).

An increase in average age at marriage has been offered as a reason for reductions in fertility in the $19^{\text {th }}$ century (Haines 2000), however is not applicable for early $20^{\text {th }}$ century fertility. The singulate mean age at marriage ${ }^{7}$ (SMAM) for females was declining though the first three decades of the $20^{\text {th }}$ century; SMAM was equal to 23.8 in 1900, 23.4 in 1910, 22.7 in 1920 and 21.2 in 1930 (Haines 2000 and U.S. Bureau of the Census 1931).

Easterlin (1961) argues that the early $20^{\text {th }}$ century fertility decline was driven by reductions in fertility among the foreign born and rural populations. Changes in

\footnotetext{
${ }^{7}$ The Singulate Mean Age at Marriage is not the straightforward mean age of marriage. Rather it compares the age-specific proportions of the single population to the married population to calculate the average age at which the transition from single to married was made.
} 
immigrant demographics, specifically the shift of immigrants from eastern and southern European countries to immigrants from the western and northern European countries, changes in the foreign-born sex ratio and an aging of the female foreignborn population resulted in declines in foreign-born fertility. Easterlin pointed to depressed agricultural conditions as causing the lower fertility among the rural populations, and also mentions the migration of individuals from high-fertility rural areas to low-fertility urban areas as a reason for why U.S. fertility declined in the relatively prosperous 1920s. However, declines in rural fertility fail to explain the trends within and between the large U.S. urban areas. For those cities with large foreign-born populations, changes in foreign-born fertility may be drive the changes in urban fertility. However, many large U.S. cities had immigrant populations below 10 percent, so it is unlikely this is the case for all urban areas. Additionally, given the attention the foreign-born population received in the Children's Bureau reports, it is likely immigrants were also a focus of the public health education programs. So part of the reduction in foreign-born fertility may be a result of these public programs.

Although there has been much work in the economics and demographic literature to understand both how individuals make fertility decisions and how the fertility trends have evolved over time, there has been relatively little work to understand why fertility differs across urban localities in the United States. An exception to this is the Fishback et. al (2007) paper that finds New Deal relief positively influenced fertility, likely bringing it back to its long term trend.

Part of the reason different cities experienced different fertility outcomes during the 1920s may be due to differences in investment in public programs. However, during this time there were no large scale federal relief programs. Before the New Deal, poor relief, public health, and other public goods were distributed at 
the state, municipal and county level. There were three programs in particular that may have caused the fertility outcomes across the cities to vary.

Public health education programs during the 1920s were directed towards women and children with the goal of reducing infant and child mortality. However, they may have also had the unintended effect of reducing fertility. This may have been effected by either direct or indirect mechanisms.

If the public health education programs did indeed reduce mortality, which it seems they did (Fox 2011, Ewbank and Preston 1989), then through this path they reduced the incentives to replace or hoard children, as well as reduced the expected cost of raising a surviving child. The replacement and hoarding effects would lead to lower fertility in areas with more public health education spending, while reducing the expected cost of raising a surviving child would tend to increase municipal fertility.

Changing individual perceptions about long term health outcomes may also be a method through which health education influenced fertility. If health education caused a perception of healthier children with higher probabilities of survival until childbearing, then the incentive to increase fertility to insure against the failure to pass on parental genes would be decreased.

Public health education programs may have also affected fertility in the different cities more directly. These programs advocated the use of breastfeeding over formula, which would directly reduce fecundity in new mothers (Bongaarts 1987, John, Menken and Chowdhury 1987). Additionally, these programs believed in the importance of smaller families as a way to reduce infant mortality (Duke 1915), so may have advocated the use of birth control or greater birth spacing among multiple child families.

Poor relief programs also varied in their existence and intensity across and 
between urban areas in 1920s America. Relief programs targeted towards the poor in general and towards single mothers and children in particular may also explain why fertility outcomes differed across areas. Payments directed towards poor mothers and children would reduce the individual cost of a child, so may tend to increase fertility. Conversely, a social insurance program may lower fertility by reducing the need for large families.

The decade of the 1920s is a particularly interesting time for studying fertility trends in American urban areas. Fertility differed widely across and within municipalities, and many cities experienced below replacement fertility for the first time. Additionally, the absence of federal welfare and public health programs meant that there was great variation in both the existence and the intensity of these programs across areas. Whether it was the presence or absence of these programs that caused fertility to decline to a greater extent in some cities than others and which of these programs influenced fertility to the greatest extent are empirical questions. With the use of a ten year panel of municipalities between 1923 and 1932 that includes information on these different types of programs as well as fertility information, we attempt to answer them.

\section{Data}

We evaluate the relative and absolute effects of the public health education and poverty relief programs on fertility for a set of American municipalities that both had a population of over 100,000 in 1920 and were part of the Birth Registration Area in a given year. The period under consideration is 1923 to 1932, chosen both for data availability reasons and to eliminate the effect of any New Deal programs enacted after 1932. Information on the amount of spending distributed to these types of 
programs is obtained from the Financial Statistics of Cities volumes, published by the Department of Commerce. These volumes also contained data regarding city expenditures on sanitation, health, and education. Per capita summary statistics adjusted to 2007 dollars for each of the spending variables are given in the top panel of Table 1. Population data were also collected from the Financial Statistics of Cities volumes, and when missing, interpolated between the nearest two years. ${ }^{8}$

Three municipal spending variables are of primary interest. These are the spending on public health education in a city, the spending on welfare for children and mothers and the spending on outdoor care of poor. Spending on public health education includes expenditures on the medical inspection of school children, for education about proper hygiene, milk preparation techniques and for other things that could be done to conserve child life. Money distributed under the "medical inspection for school children” category helped pay for physician and nurse visits to distribute information and perform physical examinations. School children were not treated, but parents were informed if any defects were found.

Spending on welfare for children and mothers includes spending on mothers' pensions, funding for almshouses and orphanages and other charitable spending for children. Mothers' pensions distributed transfer payments to widows with dependent children. Charitable spending for children was directed towards children in institutions or towards care of those without parents.

Outdoor care of poor differed in its administration across cities, but typically involved relief to individuals or families that due to unemployment, illness, accident,

\footnotetext{
8 The cities interpolated were: Los Angeles, CA, 1924-1927; Seattle, WA, 1924-1927; Portland, OR 1925-1927; Akron, OH 1924-1927; Bridgeport CT, 1924-1927; New Bedford, MA, 1926-1927; Norfolk, VA , 1924-1925; Lowell, MA, 1926-1927; Lawrence, MA, 1926-1927; Elizabeth, NJ, 19241927; Erie, PA, 1924-1927; Waterbury CT, 1924-1927; Jackson, FL, 1926-1927; Hoboken, NJ, 19231925; Brockton, MA, 1926-1927; Davenport, IO, 1926-1927; Haverhill, MA, 1926-1927; Wheeling, WV, 1923-1927; Superior, WI, 1923-1927; Auburn, NY, 1926-1927; Newport, VA, 1923-1924.
} 
or other reasons, were temporarily dependent. It also sometimes involved the giving of aid more or less permanently, when it seemed desirable to keep a family together instead of scattering its members among institutions (Smith 1932, Lancaster 1937). It was under this category that cities distributed relief to individuals unemployed during the Great Contraction between 1929 and 1932. Unemployment is known to be correlated with fertility (Sobotka, Skirrbekk and Philipov 2011), so it will be important to examine to what extent the relationship estimated between outdoor care of poor and fertility is a result of the relationship between economic conditions and fertility.

Adjusted to 2007 dollars, an average city in the dataset spent about \$3.41 per person on health programs for children, about \$5.05 on charity for children and about \$12.89 per person on outdoor care of poor. The size of the mean per capita outdoor care of poor spending value is due to significant growth at the end of the period. To illustrate this, figures 3, 4 and 5 plot the per capita spending trends of public health education, welfare for children and mothers and outdoor care of poor respectively. Spending in all three categories increased throughout the 1920s and early 1930s, outdoor care of poor substantially so. The sizable increases between 1929 and 1932 were likely a result of the fact that until the full implementation of the Social Security Act, outdoor care of poor payments were used as unemployment insurance in many of the areas. It is not immediately evident from figure 3, but every city in the panel spent at least a small amount on public health education each year. This was not the case for the spending on charity for children and mother or outdoor care of poor. Eleven cities in the data set distributed no money towards spending on charity for children and mothers over the entirety of the panel. Another ten cities had periods of zero spending, although in at least one year during the panel distributed at least some 
money through this category. Residents in some cities also experienced periods of time with no spending on outdoor care of poor. Between 1923 and 1932, seven cities had periods of zero spending in this category. Scranton, PA and Omaha, NE were the final adopters of outdoor care of poor as they waited until 1929 and 1930, respectively, to begin payments.

Cities that spent more on public health education, charity for children and mothers and outdoor care of poor potentially experienced different trends in fertility than those that spent less. Figures 6 through 8 stratify the sample cities between those in the top quartile and those in the bottom quartile for each of those three spending categories and plot the mean-differenced trends for each of the two groups. Figure 6 plots the annual mean-differenced fertility trends within cities in the top and bottom quartiles of aggregate health education spending between 1923 and 1932. At the beginning of the panel, cities in the top quartile of health education on average had higher than average fertility rates, while fertility in cities in the bottom quartile was below average. However, fertility declines within those cities at the top quartile of health education spending caused the gap to narrow considerably by 1932. Extending this analysis through the 1930s would show that by 1937 cities in the top quartile had lower than average fertility while cities in the bottom quartile experienced higher than average fertility. A similar story occurs in figure 8, which plots the annual meandifferenced fertility trends within cities in the top and bottom quartiles of aggregate outdoor care of poor spending between 1923 and 1932. Cities in the top quartile of outdoor care of poor spending had fertility rates much higher than average, while cities at the bottom had lower than average fertility. As fertility fell relative to the average in cities in the top quartile, fertility rose relative to the average in cities in the bottom quartile and by 1932 the gap had narrowed. This pattern did not hold for cities 
in the top and bottom quartiles in spending on charity for children and mothers, displayed in figure 7. Cities in the bottom quartile of spending towards charity for children and mothers on average had slightly higher fertility than average, while cities in the top quartile generally had lower fertility than average. Aside from the three years 1927 through 1929, the gap between the two mean-differenced trends stayed fairly constant.

Figures 6 through 8 suggest that cities which spent more on public health education and outdoor care of poor experienced fertility declines relative to the average, while the opposite was true for cities which spent less. Cities that spent little on charity for children and mothers did not appear to perform differently than cities in the top quartile of spending in this category. To evaluate this further, table 2 gives the basic correlations between each of the spending variables and TFR*. Interestingly, there is a positive correlation between public health education and fertility and negative relationships between charity for children and mothers and outdoor care of poor and fertility. The positive coefficient on public health education spending is likely a result of the selection evident in figure 6. Cities which had higher fertility relative to the average were also those which spent more on public health education. This selection effect is also likely present for the correlations between fertility and charity for children and mothers and fertility and outdoor care of poor. That a city which spent more on outdoor care of poor also tended to have higher fertility relative to the average suggests that the correlation in table 2 understates the true effect on fertility from the provision of outdoor care of poor.

In addition to the selection effect, these basic correlations will not represent the causal effect if spending on public health education and poor relief are at all correlated with any other factors that influence fertility. This is a strong assumption 
since it, among other variable relationships, assumes educational spending or a city's demographic structure do not influence fertility and public health education jointly. If charitable and public health spending levels were greater in cities with more per capita income and per capita income was correlated with lower fertility rates, then failing to include a measure of income would lead to a negative bias. Because of this, other data in addition to that collected from the Financial Statistics of Cities volumes is necessary. Information on income and wealth in the different cities is of particular importance. Personal income information is unavailable at the city level prior to 1940, so we use average annual earnings from the manufacturing sector to proxy for income. These are obtained from the Biannual Census of Manufactures volumes. ${ }^{9}$ Using manufacturing wages in the different cities will help control for differences in economic conditions that may confound the relationship between outdoor care of poor and fertility. From table 1, average manufacturing wages when adjusted to 2007 dollars were about $\$ 15,500$. Although this seems low, it was close to the level of $\$ 1,500$ nominal dollars seen as the middle-class threshold by child advocates (Duke 1915). To control for differences in the distribution of income, an additional measure of the number of tax returns filed as a share of the municipal population in a year was collected from series published by the U.S. Bureau of Internal Revenue (U.S. Bureau of Internal Revenue 1923-1932). This gives the number of jointly filing couples in each city with incomes above \$5,000 (about \$60,000 in 2007 dollars), and individual filers with incomes over $\$ 2,000$. Typically only about 6.5 percent of the population in the different cities filed taxes. The city with the highest proportion of filers was Los Angeles, with nearly a fifth of its population filing returns in 1923.

The demographics of a city are also possibly correlated with both public health

\footnotetext{
${ }^{9}$ For the odd numbered years we use a weighted interpolation between the closest even numbered years, using state per capita income as the weights.
} 
and poor relief spending and fertility. The foreign born population generally had much higher fertility than did the native population, and also typically experienced worse health and economic outcomes (Duke 1915, Dempsey, 1919, Hughes 1923). To control for changes in the population structure and other possible confounding demographic variables, municipal demographics were collected from the decennial censuses and interpolated for the intercensal years. These include information on population density, minority concentrations and literacy rates. Demographic information is from the Decennial Censuses and interpolated for annual estimates. Lastly, information on the number of manufacturing workers employed in each city, as well as the proportion of workers working in polluting industries were collected from the Census of Manufactures volumes. Indicators for the date when suffrage was enacted in each state will also be included in the analysis. The timing of suffrage varied across states and may indicate the level of female empowerment in the different areas.

\section{Model and Results}

From figures 6 through 8 and table 2 it is evident there is likely selection between the extents to which cities chose to participate in the different public programs and their starting level of fertility. It could be as simple as cities with high mortality choosing to invest more in public health, or it could be a more complicated selection issue such as the culture or beliefs of a population affecting both the levels of fertility and the extent to which investments in public health and poor relief were made. We can observe and therefore control for higher levels of mortality affecting both spending and fertility, but differences in culture and beliefs, especially at local 
levels, are more difficult to measure. ${ }^{10}$ Because of this selection, basic correlations, even conditional correlations obtained from an ordinary least squares regression, would be biased. Given this, it is important to control for unobserved factors that potentially influence both fertility and the spending on public programs in the different municipalities. Assuming that these unobserved factors that vary jointly with fertility and expenditures are not trending through time, it is possible to identify the relationship between these public programs and fertility using each city's within variation. Exploiting the panel structure of the data, we utilize this within variation through the use of a fixed effects model, defined below. ${ }^{11}$

$$
\begin{aligned}
\operatorname{TFR}_{i, t}^{*}= & \beta_{1} \mathrm{PHE}_{i, t-1}+\beta_{2} \mathrm{CCM}_{i, t-1}+\beta_{3} \mathrm{COut}_{i, t-1}+\beta_{4} \mathrm{IMR}_{i, t-1} \\
& +\sum_{j=1}^{J} \beta_{j+5} X_{j, i, t-1}+\beta_{J+6} C_{i}+\beta_{J+7} Y_{t}+\varepsilon_{i, t}
\end{aligned}
$$

The dependant variable is the estimated total fertility rate, TFR*, in city $i$ and year $t$. The first three independent variables represent prior year spending for each of the three different types of public programs under analysis. $P H E_{i, t-1}$ is the amount of per capita spending on public health education in city $i$ and year $t, C C M_{i, t-1}$ is the amount of per capita spending on charity for children and mothers in city $i$ and year $t$ and $\mathrm{COut}_{i, t-1}$ is the amount of per capita spending on outdoor care of poor in city $i$ and year $t$. To control for any influence mortality may have had on public program spending and fertility, the lagged infant mortality rate, $I M R_{i, t-1}$ is included. $\sum_{j=1}^{J} \beta_{j+5} X_{j, i, t-1}$ is a set of $\mathrm{J}$ covariates that include the city demographic variables percent black, percent illiterate, percent rural, and the population density of the

\footnotetext{
${ }^{10}$ An attempt to understand whether changes in religious populations during this time explain changes in fertility is currently underway.

${ }^{11}$ By estimating the dependent variable, there is necessarily some level of measurement error. It is possible this error is correlated with some of the dependent variables, so alternative specifications using the General Fertility Rate were also estimated. The results were qualitatively the same.
} 
surrounding county. Also included in $X$ is the amount of prior year per capita spending on sanitation, hospitals, education, health other than child health, and other charitable spending. It contains the income and income distribution measures, as well as the proportion of workers in polluting industries and the suffrage variables.

Certainly there are other factors not controlled for with the above set of covariates. If these are jointly correlated with the spending variables of interest and fertility, then the model will not be identified. For example, if the religious composition of a city is changing, and these changes are positively associated with both poor relief spending and fertility, there will be a positive bias on the coefficient for outdoor care of poor. Time-varying omitted variables can still confound estimates from the above fixed effects model. However, anything that is constant through time, such as geographic location, will be controlled for by the set of city fixed effects, represented in the model by $C_{i}$. Nationwide shocks common to all cities in the sample, due to changes in national optimism, shocks to national income, or other factors, are controlled for with period effects, represented by $Y_{t}$. Figure 2 suggests a common positive shock to fertility across most of the different cities in 1924, so controlling for these period effects will be important. The errors are assumed to have conditional mean zero and are the unobserved characteristics affecting fertility in city $i$, year $t$. In the estimation, these are clustered at the census region level to account for regional differences in climate, geography and economy.

Estimates from this model are given in table 3, along with the dollar cost per unit change associated with the coefficient estimates for expenditures on the three public programs. The dollar cost per unit change is also included for the coefficient estimates on expenditures for other health, schools and libraries and manufacturing wages per worker. 
Expenditures on both public health education and outdoor care of poor are negatively and statistically significantly associated with declining fertility in the different cities. Additionally, both are economically significant with spending on public health education slightly more so. Approximately $\$ 4.30$ dollars of per capita health education spending or about $\$ 37.40$ of per capita spending on outdoor care of poor were associated with reducing TFR* by 0.1 . Average annual per capita expenditures on these public programs were about $\$ 3.41$ and 12.89 respectively, so these coefficient estimates translate to reductions in fertility of about 0.08 and 0.03 in a year. This suggests that cities spending in the $75^{\text {th }}$ percentile on health education experienced a $1.95 \%$ faster fertility decline than cities spending in the $25^{\text {th }}$ percentile. For poor relief the difference was $1.45 \%$

It is interesting that both coefficients on public health education and outdoor care of poor spending are negative. Through either improved perceptions of long term health outcomes, declines in mortality, encouragement of breast feeding and smaller families and possible increased access to fertility control, the public health education programs implemented across many of the different cities led to significant decreases in fertility throughout the 1920s. ${ }^{12}$ Outdoor care of poor is a sort of social insurance program, so it is somewhat surprising that this effect is also negative. This finding differs from other papers which have found that poor relief or unemployment insurance is positively related to fertility (Fishback et. al. 2007, Hyatt and Milne 1991). However, other papers to study the effects of poor relief or social insurance on fertility have done so during periods of far different economic and demographic conditions. The 1920s were not only a period of general prosperity in urban areas, but were also a period that began with relatively high (above replacement) fertility. It is

\footnotetext{
${ }^{12}$ Interestingly, exclusion of the infant mortality rate only marginally affected the coefficient on public health education. This suggests the public health education programs did not affect fertility through their effects on infant mortality.
} 
possible we have imperfectly controlled for economic conditions, and the use of outdoor care of poor as a type of unemployment insurance in many areas may be causing this result. This would indicate fertility was pro-cyclical in cities during the 1920s, which is consistent with the recent empirical literature (Sobotka, Skirbekk, and Philipol, 2011). Additional work still needs to be done to explore whether this finding is a result of changing employment conditions in areas, if it is an insurance effect, or a trade-off between quantity and quality that is leading to this negative relationship.

Charity directed towards children and mothers does not appear to affect fertility in the different municipalities. However, given the specifics of this type of charity, this is not a particularly surprising. Charity for children is to support children in almshouses and those without support from their families, and mothers' pensions are payments distributed towards widows with children. If fertility is based off of individual or family expectations, then unless there is an expectation the father would die or the family abandon the child, it is unlikely the extent of spending on these programs would substantially affect fertility. ${ }^{13}$

Other statistically significant coefficients include the infant mortality rate, other health spending, spending on schools and libraries, manufacturing wages per worker, the number of tax returns per capita, the proportion of workers in polluting industries, the population density of the surrounding county and the percent of individual who were foreign born. Of these, only the variables for the Infant Mortality Rate, spending on schools and libraries, and the percent foreign born are economically significant. The coefficient on the infant mortality rate is economically significant, yet still only explains a small portion of the fertility decline. Across all of the cities, infant mortality declined from an average of 78.5 in 1923 to an average of

\footnotetext{
${ }^{13}$ Including an indicator for whether or not a city distributes any payments towards mothers' pensions at all (fourteen cities in the sample do not during some period in the sample) is statistically significant and negative.
} 
55.9 in 1932. The average annual decline of the Infant Mortality Rate then being about 2.25, the estimated coefficient of 0.00256 implies a 0.0058 reduction in TFR* (about $-0.25 \%$ from the 1923 average TFR* of 2.57). Manufacturing wages are positively related to fertility, but would on average effectively need to double to create a 0.5 increase in TFR*. Additionally, if the proportion of people filing taxes increased from 20 percent to 30 percent, then that would only increase the TFR by about 0.12 . Conversely, if the number of foreign born individuals living in a city increased by 5 percent, that is associated with about a 0.28 point increase in TFR* Spending on schools and libraries is also positively related to fertility in a city, consistent with fertility theories regarding changes in the expected cost of raising a child. For a sense of the magnitude, the city which spent the least per capita on schools and libraries in a given year spent was about $\$ 300$ less than the city which spent the most. Ceteris paribus, this translates into about a 0.5 unit increase in the TFR's difference between those two cities in the following year. These are not meaningless magnitudes, however they are all lower than those estimated for the key spending variables.

\section{Sensitivity Analyses}

To check the sensitivity of the results to different model specifications, we estimate three different variations of the model in Section 5. The first of these replaces the dependent variable TFR with a scaled version of the General Fertility Rate (GFR). Because the age-specific rates are calculated using information for the whole United States in 1933, it is possible measurement error systematically enters TFR*. To test this, we estimate a version of the model using the number of children per woman aged 15 to 44 as the dependent variable. To construct the GFR, typically this ratio is multiplied by 1,000 . We instead scale it by 30 to allow comparison to the 
estimates in Table 3. Future versions of the paper will also include a set of controls for the age structure of each city's population, but for now these are not included. Estimates from this model are given in the first column of Table 4. In every case, the coefficient estimates are very similar across the two models using the different dependent variables. Since changes in the GFR tend to highly correlate with changes in TFR*, it is not particularly surprising that the coefficient estimates are consistent between the two specifications.

The second column of Table 4 contains coefficient estimates from the second specification test. From Figure 5, it is clear that with the onset of the Great Depression in 1930, cities considerably expanded relief spending through outdoor care of poor. To try to eliminate the effect of the expanded spending on fertility, we also estimate the model in Section 5 using only the years 1923 through 1930. Because all of the spending variables are lagged and this estimates the spending effects using spending data between 1923 and 1929, limiting the analysis to years before 1931 should remove the effect of the expanded spending in response to the New Deal. From the second column of Table 4, the estimates do suggest that eliminating 1931 and 1932 from the analysis attenuates the coefficient estimates for the spending variables of interest. Both coefficients on public health education spending and outdoor care of poor spending are cut in half, and in the case of the former, is no longer statistically significant at the 10 percent level. The coefficient on outdoor care of poor remains statistically and economically significant. Regarding the lack of significance for the coefficient on public health education, it is important to remember that there is less variation across areas and time in its spending. Given this, it will be more sensitive to the expulsion of large sets of observations. Removal of the first two years in the sample, 1923 and 1924, from the analysis also yields an imprecise 
estimate for the coefficient on public health education spending. Given this, it is desirable to diminish the impact of the increase in outdoor care of poor spending in 1931 and 1932 while still including those years in the analysis. To this end, we instead estimate the model using the logged value of per capita outdoor care of poor spending. These results are given in Column 3 of Table 4, and are consistent with the results derived from the model in Section 5.

\section{Concluding Remarks}

Aside from the baby boom of the 1940s and 50s and evidence of recent increases, ${ }^{14}$ fertility in the United States has been declining since at least the mid1800s. A variety of reasons for this overall negative trend have been offered, many centered around the idea of migration from high-fertility rural areas to low-fertility urban areas in the nineteenth and early twentieth centuries. However, this fails to explain why fertility trends within large American urban areas differed so substantially. Figure 2 demonstrated the substantial variation across areas between 1923 and 1932, and this has continued to be the case in the United States. Differences in investment in certain types of public programs, specifically public health education and outdoor care of poor, offer one potential reason why different cities experienced different fertility outcomes in the 1920s and early 1930s.

Although these programs were not instituted as a means for reducing fertility, it appears they had the unintended effect of doing so. Fixed effects estimates indicate that expenditures on both public health education and outdoor care of poor were both statistically and economically significantly related to reductions in fertility. Adjusted to 2007 dollars, approximately \$43 per capita spent on public health education was

\footnotetext{
${ }^{14}$ Myrskyla, Kohler and Billari (2009) document recent increases in fertility rates for highly developed countries
} 
associated with reducing the Total Fertility Rate by one. About $\$ 374$ per capita spent on outdoor care of poor was associated with an equal effect. For cities part of the Birth Registration Area and over 100,000 persons in 1920, this translated to about 3 percent annual reduction in fertility for cities at the average of per capita public health education spending (about \$3.41). For cities at the average of outdoor care of poor spending (about \$12.89), this translated to an average annual reduction in fertility of about $1.1 \%$. The differences in investment in these two public programs help to understand why a city such as Camden, NJ, which invested below average amounts in both public programs, experienced little difference in its fertility rate throughout the 1920s, while Fall River, MA, a city which invested above average amounts in these programs, began the decade with higher fertility, but ended the 1920s with much lower fertility.

These programs, especially those of public health education, were instituted as a way to combat high mortality, particularly that of infants. It is unlikely these programs were intended to reduce fertility, as the motivations surrounding infant mortality included growing the U.S. population. However, although the effects of the public health education and poor relief programs on fertility were very likely unintended, they were significant and strong. 


\section{References}

Becker, Gary S. and Robert J. Barro. (1989) "Fertility Choice in a Model of Economic Growth. Econometrica, Vol. 57(2): 481-501.

Becker, Gary S. and Nigel Tomes. (1976) "Child Endowments and the Quantity and Quality of Children.” Journal of Political Economy, Vol. 84(4), Part 2: Essays in Labor Economics in Honor of H. Gregg Lewis: S143-S162.

Bongaarts, John. (1987) “The Proximate Determinants of Fertility.” Technology in Society, Vol. 9: 243-260

David, Paul A. and Warren C. Sanderson. (1987) "The Emergence of a Two-Child Norm among American Birth-Controllers.” Population and Development Review, Vol. 13(1): 1-41.

Dempsey, Mary V. (1919) "Infant Mortality: Results of a Field Study in Brockton, Mass. Based on Births in One Year.” Children’s Bureau Publication No. 37. Government Printing Office. Washington, D.C.

Doepke, Matthias. (2004) “Accounting for Fertility Decline During the Transition to Growth. Journal of Economic Growth, Vol. 9: 347-383.

Duke, Emma. (1915) "Results of Field Study in Johnstown, PA., Based on Births in One Calendar Year. Children’s Bureau Publication No. 9. Washington, Government Printing Office

Easterlin, Richard A. "The American Baby Boom in Historical Perspective.” The American Economic Review, Vol. 51(5): 869-911.

Eckstein, Zvi, Pedro Mira and Kenneth I. Wolpin. "A Quantitative Analysis of Swedish Fertility Dynamics: 1751-1990. Review of Economic Dynamics, Vol. 2(1): 137-165.

Ewbank, Douglas C. and Samuel H Preston. (1989) "Personal Health Behavior and the Decline in Infant and Child Mortality: The United States, 1900-1930.” Pp. 116-149 in What We Know About Health Transition: The Cultural, Social and Behavioural Determinants of Health; Proceedings of an International Workshop, edited by J.C. Caldwell.

Fox, Jonathan F. (2011) "Public Health Movements, Local Poor Relief and Child Mortality in American Cities: 1923-1932.” MPIDR Working Paper WP 2011005.

Hacker, J. David. (2003) "Rethinking the 'Early' Decline of Marital Fertility in the United States.” Demography, Vol. 40(4): 605-620.

Haines, Michael R. (2000) “The White Population of the United States, 1790-1920." Pp 305-370 in A Population History of North America, edited by Michael R. Haines and Richard H. Steckel. Cambridge University Press. New York, NY. 
Haines, Michael R. and Avery M. Guest. (2008) "Fertility in New York State in the Pre-Civil War Era.” Demography, Vol. 45(2): 345-361

Hirschman, Charles. (1994) "Why Fertility Changes.” Annual Review of Sociology, Vol. 20: 203-233.

Hoffman, Frederick, L. (1909) “The Decline in the Birth Rate.” The North American Review, Vol. 189(642): 675-587.

Hughes, Elizabeth. (1923) "Infant Mortality: Results of Field Study in Gary, Ind., Based on Births in One Year.” Children’s Bureau Publication No. 112. Government Printing Office. Washington, D.C.

Hyatt, Douglas E. and William J. Milne. (1991) “Can Public Policy Affect Fertility?” Canadian Public Policy, Vol. 17(1): 77-85.

Fishback, Price V., Michael R. Haines and Shawn Kantor. (2007) "Births, Deaths and New Deal Relief During the Great Depression.” The Review of Economics and Statistics, Vol. 89(1): 1-14.

John, A. Meredith, Jane A. Menken and A.K.M. Alauddin Chowdhury. (1987) “The Effects of Breastfeeding and Nutrition on Fecundability in Rural Bangladesh: A Hazards-Model Analysis.” Population Studies, Vol. 41(3): 433-446.

Jones, Larry E. and Michèle Tertilt. (2006) “An Economic History of Fertility in the U.S.: 1826-1960. NBER Working Paper No. 12796.

Lancaster, Lane W. (1937) Government in Rural America. D. Van Nostrand Company, Inc. New York.

Lathrop, Julia C. (1919) "Income and Infant Mortality.” American Journal of Public Health, Vol. 9(4): 270-274.

Mason, Karen O. (1997) “Explaining Fertility Transition.” Demography, Vol. 34(4): 443-454.

Meckel, Richard A. (1990) Save the Babies. University of Michigan Press. Ann Arbor, MI.

Myrskylä, Mikko, Hans-Peter Kohler and Francesco C. Billari. (2009) “Advances in Development Reverse Fertility Declines.” Nature, Vol. 460: 741-743.

Newmayer, S.W. (1911) “The Warfare Against Infant Mortality.” Annals of the American Academy of Political and Social Science, Vol. 32(2): 288-298

Newsholme, Arthur and T.H.C. Stevenson. "The Decline of Human Fertility in the United Kingdom and Other Countries as shown by Corrected Birth-Rates.” Journal of the Royal Statistical Society, Vol. 69(1): 34-87. 
Okun, Barbara S. (1994) "Evaluating Models for Detecting Fertility Control: Coale and Trussell's Model and Cohort Parity Analysis.” Population Studies, Vol. 48(2): 193-222

Sah, Raaj K. (1991) “The Effects of Child Mortality Changes on Fertility Choice and Parental Welfare.” Journal of Political Economy, Vol. 99(3): 582-606.

Smith, Mary Phlegar. (1932) "Trends in Municipal Administration of Public Welfare.” Social Forces, Vol. 10(3): 371-377.

Sobotka, Tomas, Vegard Skirbekk, and Dimiter Philipov. (2011) "Economic Recession and Fertility in the Developed World.” Population and Development Review, Vol. 37(2): 267-306.

U.S. Bureau of the Census. (1975) Historical Statistics of the United States, Colonial Times to 1970, Bicentennial Edition, Part 1. Government Printing Office. Washington, D.C.

U.S. Bureau of the Census. (1931) Population, Vol. 1: Number and Distribution of Inhabitants. Fifteenth Census of the United States: 1930. Government Printing Office, Washington, D.C.

U.S. Bureau of the Census. (2011) Statistical Abstract of the United States: 2011. Government Printing Office, Washington, D.C.

United States Bureau of Internal Revenue. (1923-1932) “Statistics of Income.” United States Treasury Department.

Willcox, Walter F. (1911) "The Change in the Proportion of Children in the United States and in the Birth Rate in France during the Nineteenth Century.” Publications of the American Statistical Association, Vol. 12(93): 490-499.

Woodbury, Robert Morse. (1925) "Causal Factors in Infant Mortality.” Children’s Bureau Publication No. 142. Government Printing Office, Washington DC. 
Figure 1 - BRA States and Sample Cities
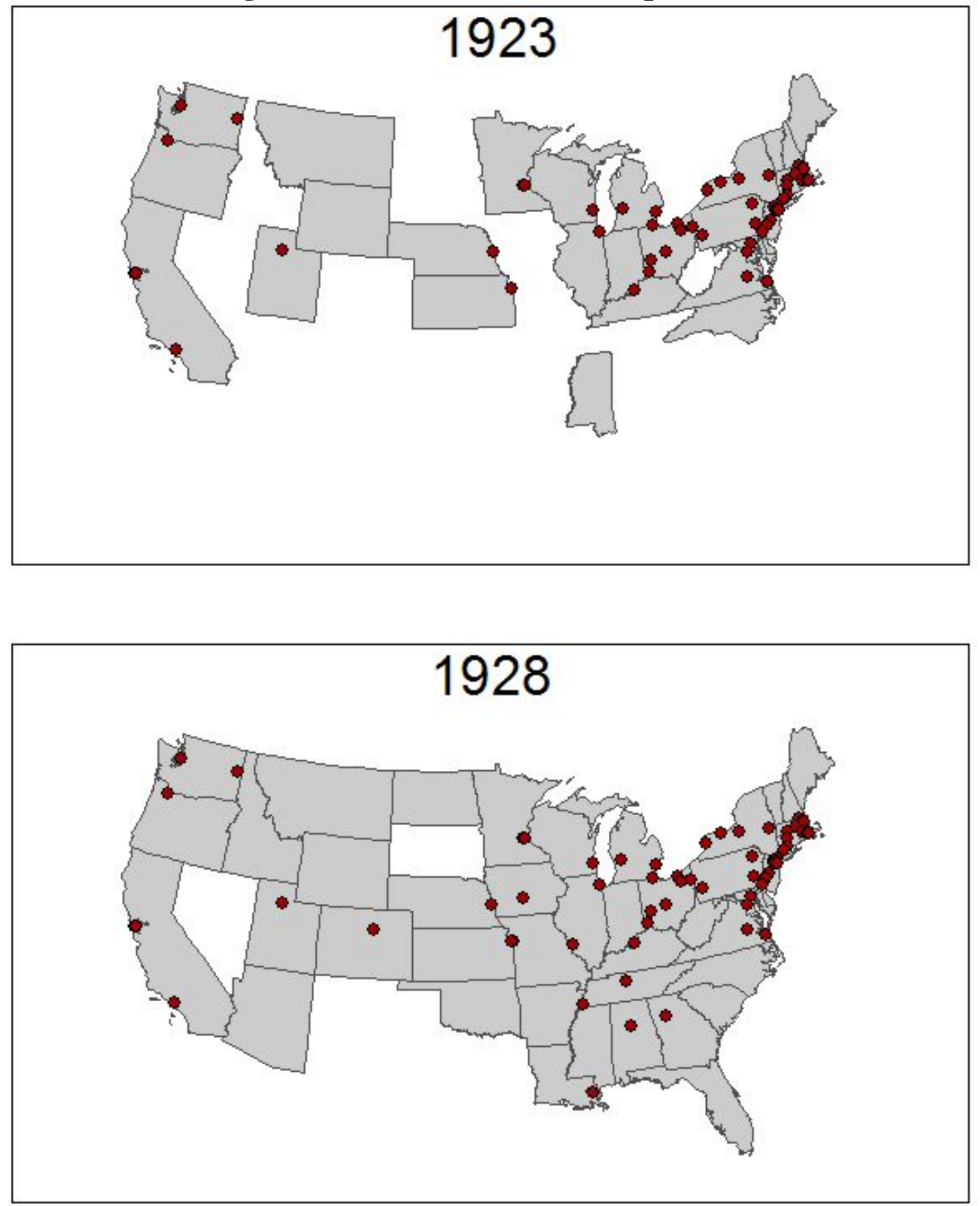
Figure 2 - Total Fertility Rate Trends, 1921 BRA Cities over 100,000

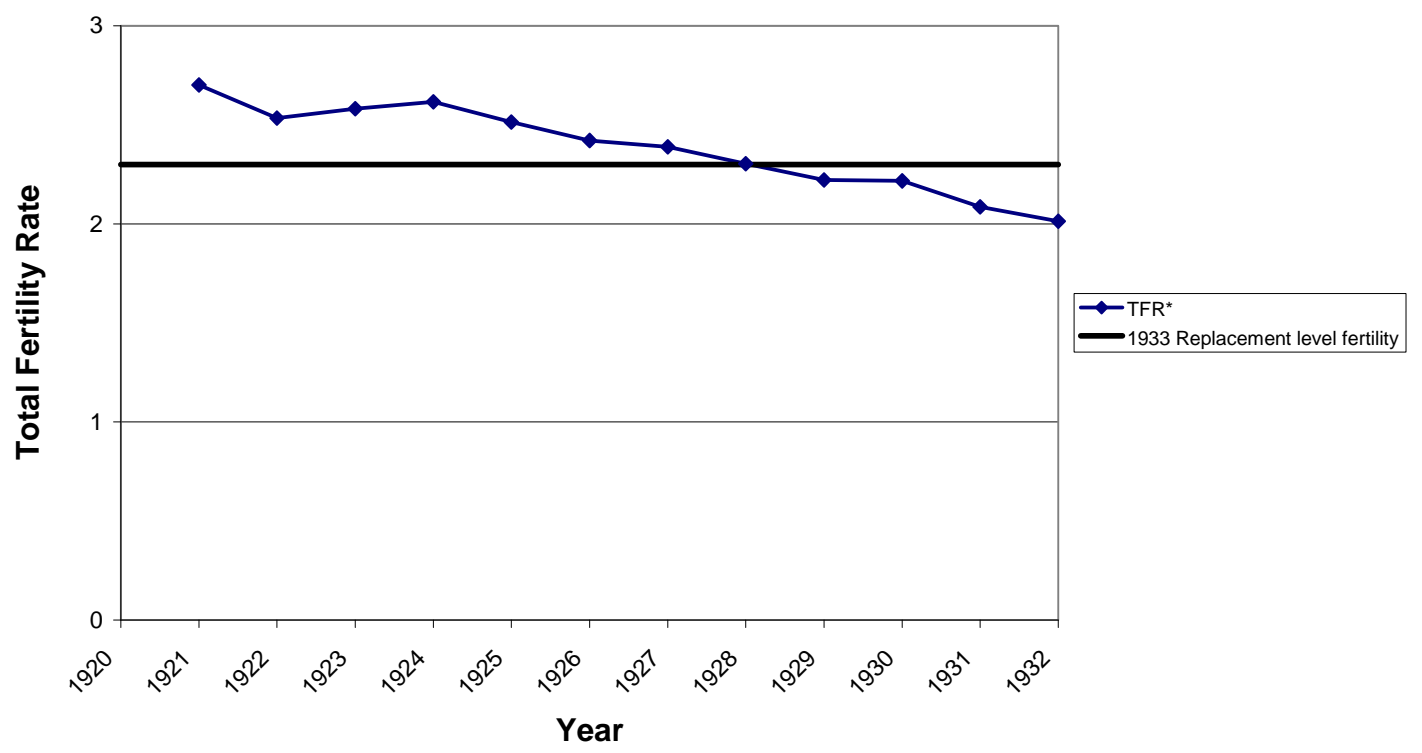

Figure 3 - Fertility Trends by City

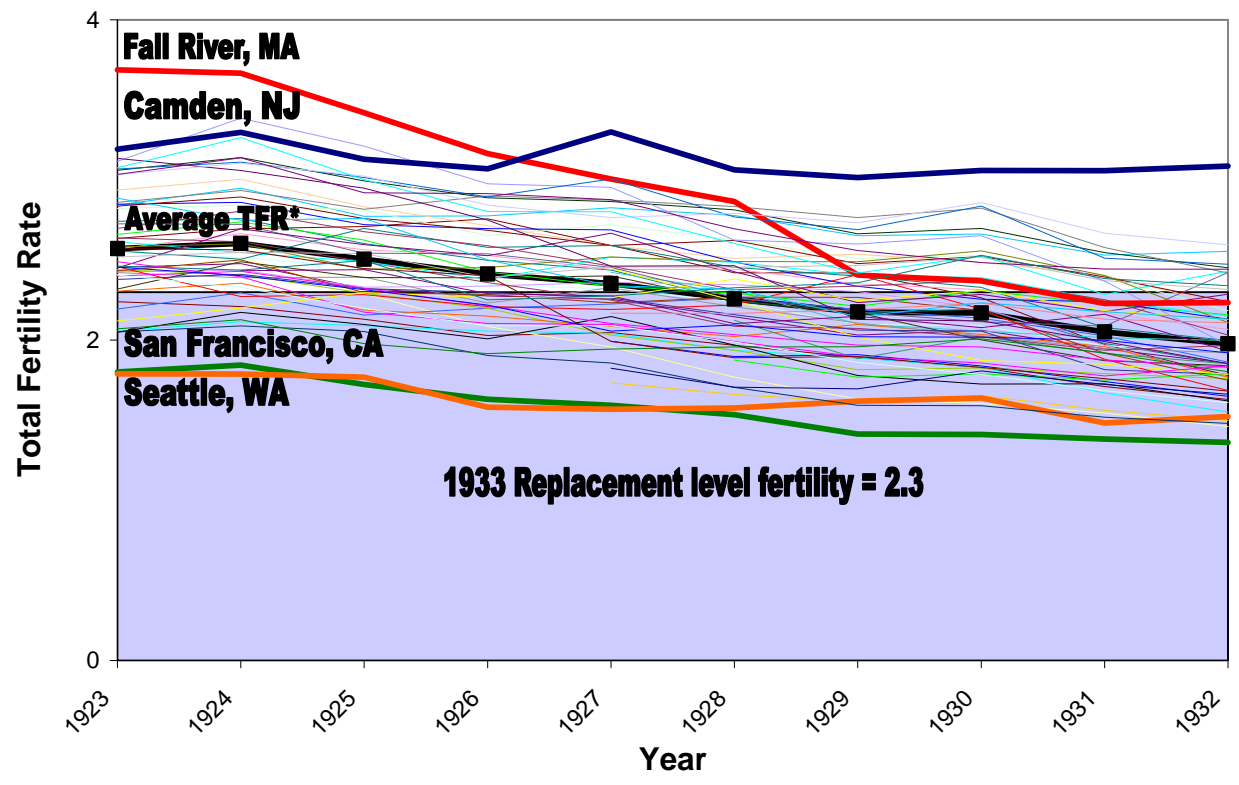


Figure 3 - PC Spending on Public Health Education

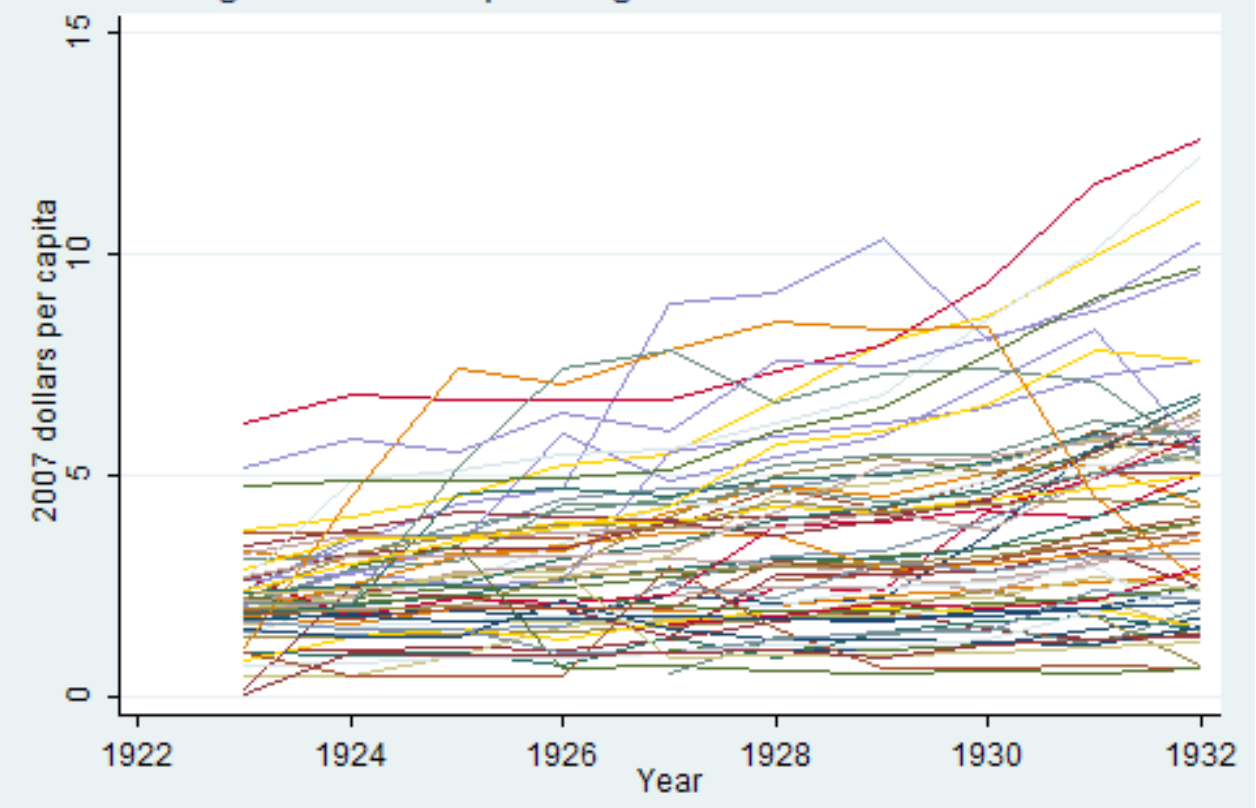

Figure 4 - PC Spending on Chrty for Child. \& Mothers

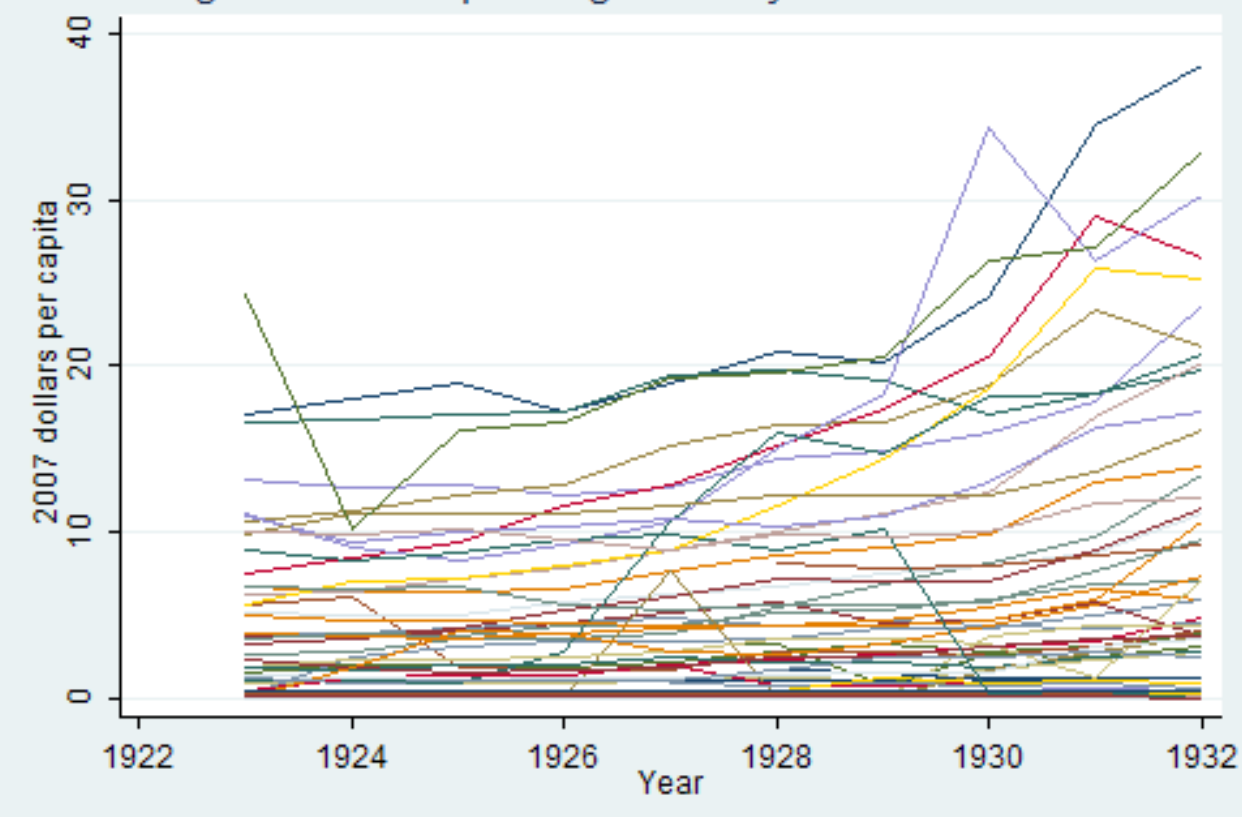


Figure 5 - PC Spending on Outdoor Care of Poor

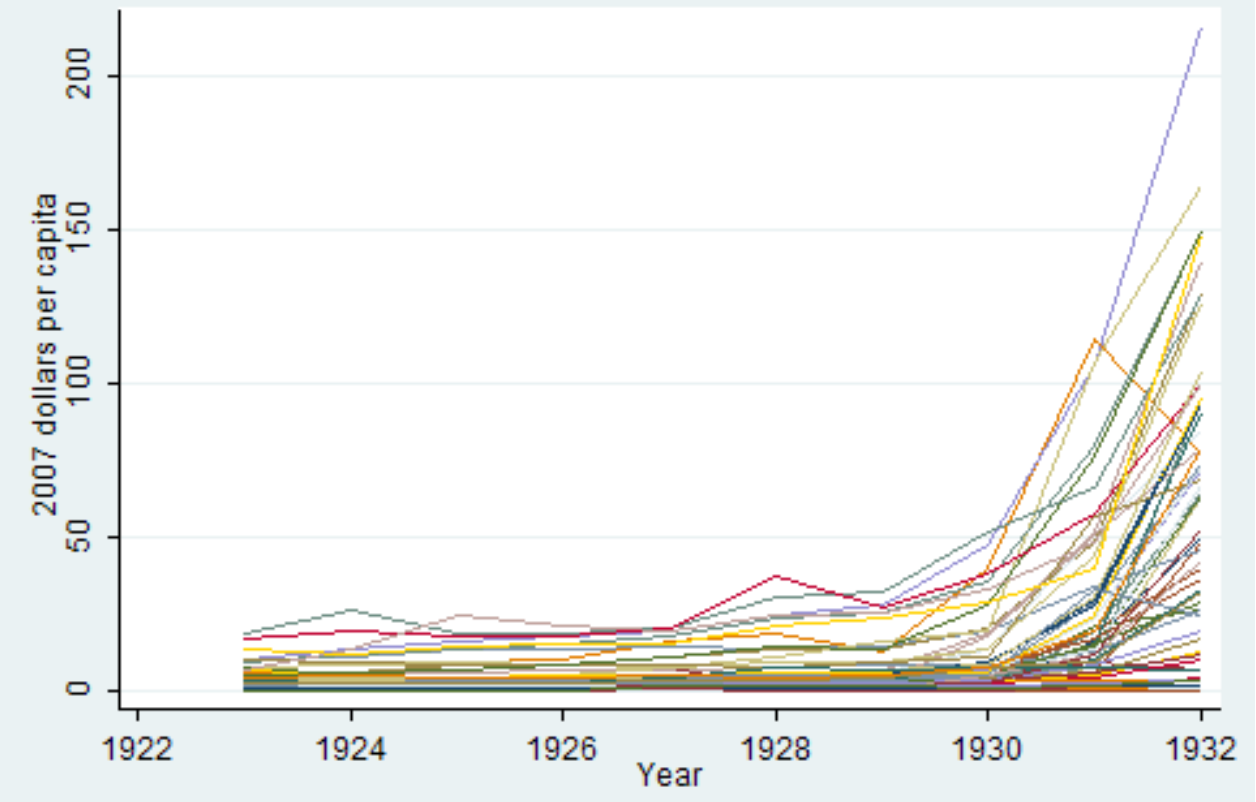

Fig 6: Fertility Trends in Cities with More and Less Public Health Education Spending

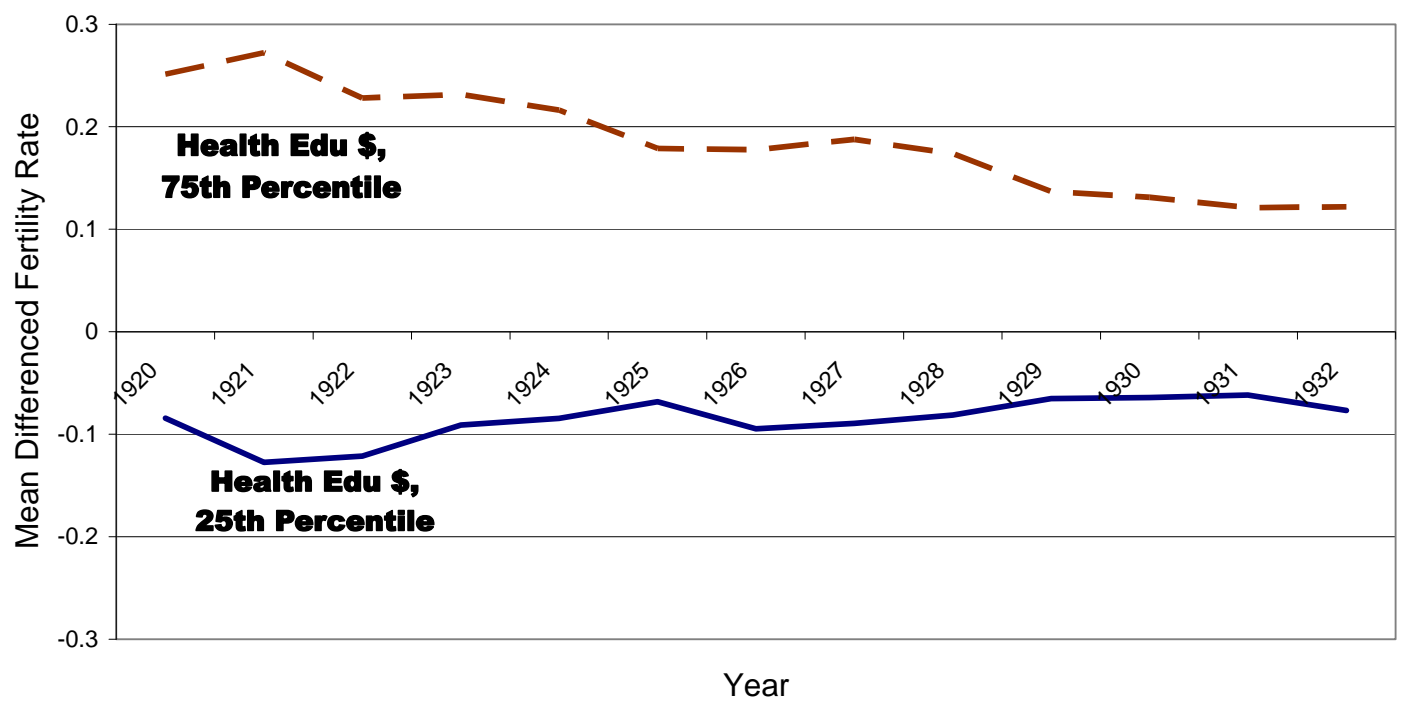


Fig 7: Fertility Trends in Cities with More and Less Charity for Children and Mothers Spending

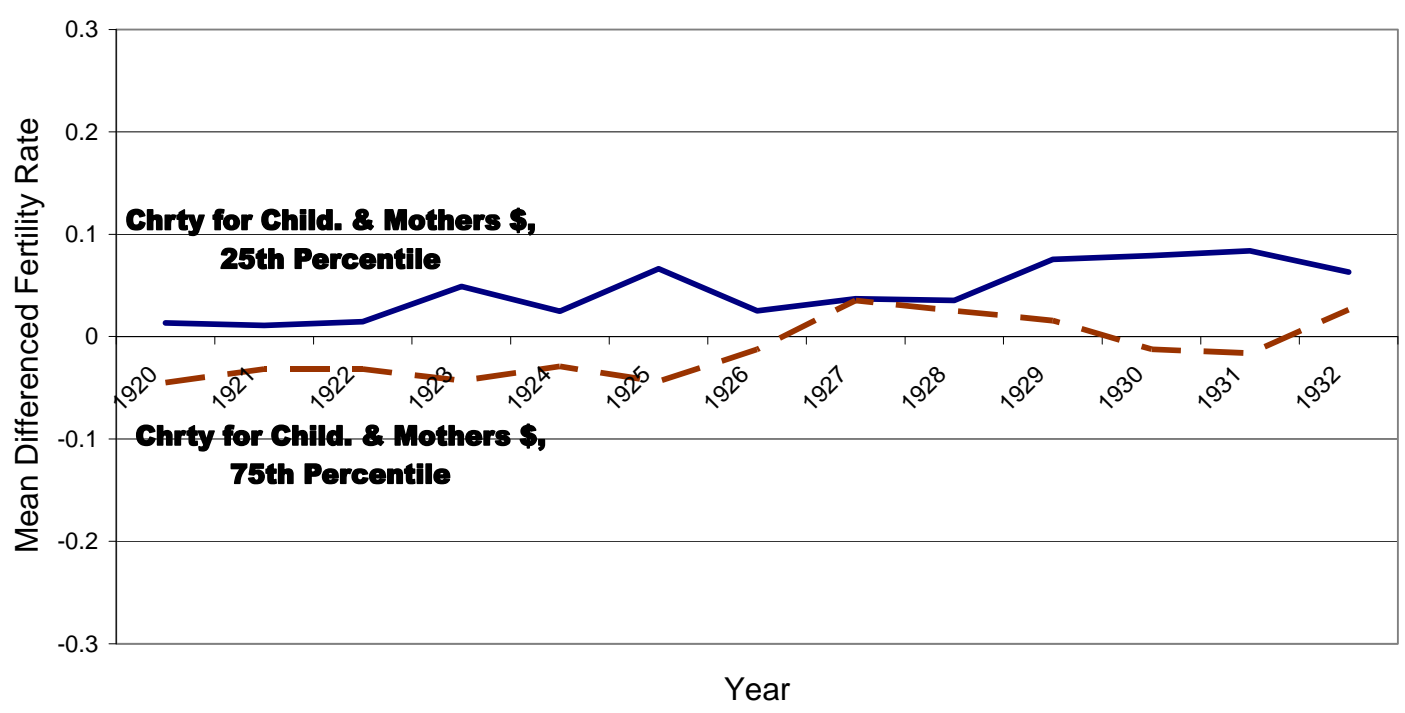

Fig 8: Fertility Trends in Cities with More and Less Outdoor Care of Poor Spending

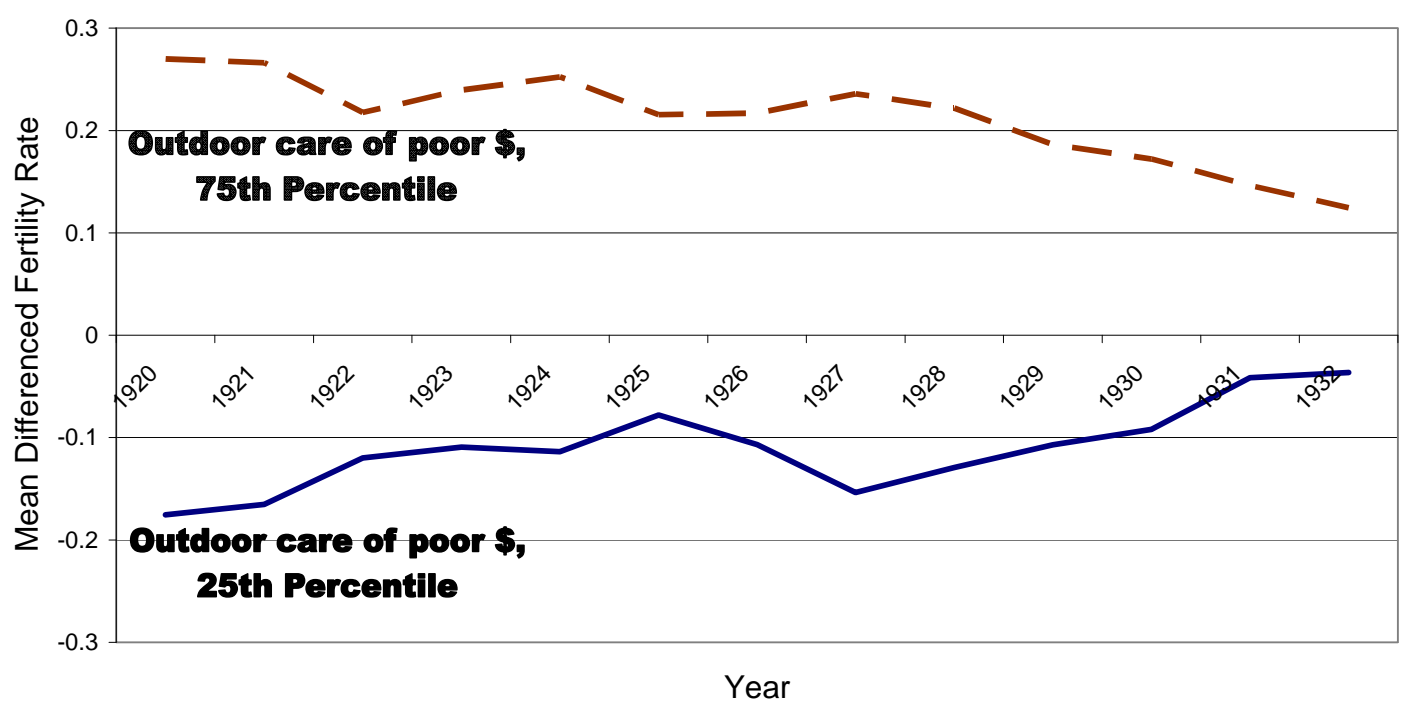


Table 1 - Summary Statistics

\begin{tabular}{|c|c|c|c|c|}
\hline Variable & Mean & Min & Max & Zeros \\
\hline \multicolumn{5}{|l|}{ Municipal Spending Variables ${ }^{1}$} \\
\hline \multicolumn{5}{|l|}{ Municipal health and welfare spending } \\
\hline Health education & $\$ 3.41$ & 0.07 & 12.63 & 0 \\
\hline Charity for children and mothers & 5.05 & 0.00 & 38.16 & 135 \\
\hline Outdoor care of poor & 12.89 & 0.00 & 216.17 & 24 \\
\hline Other health & 10.60 & 1.27 & 39.46 & 0 \\
\hline Other charity & 6.05 & 0.00 & 50.29 & 92 \\
\hline \multicolumn{5}{|l|}{ Other municipal cost payments } \\
\hline Sanitation & $\$ 33.42$ & 7.75 & 102.44 & 0 \\
\hline Hospitals & 10.44 & 0.00 & 92.04 & 101 \\
\hline Schools and libraries & 197.40 & 83.22 & 383.88 & 0 \\
\hline \multicolumn{5}{|l|}{ Personal income/Economic outcome variables ${ }^{2}$} \\
\hline Manufacturing wages per worker & $\$ 15,490.44$ & $5,389.00$ & $24,370.13$ & 0 \\
\hline Municipal tax returns per capita & 0.0645 & 0.01169 & 0.22402 & 0 \\
\hline \multicolumn{5}{|l|}{ Heavy Industry/pollution variables } \\
\hline Pct of mfg workers in heavy industry & $12.53 \%$ & $0.00 \%$ & $100.00 \%$ & 62 \\
\hline \multicolumn{5}{|l|}{ Municipal demographics ${ }^{3}$} \\
\hline Population density & $9,952.81$ & $1,694.88$ & $29,388.50$ & 0 \\
\hline Percent black & $7.06 \%$ & $0.12 \%$ & $41.73 \%$ & 0 \\
\hline Percent illiterate & $3.38 \%$ & $0.51 \%$ & $11.44 \%$ & 0 \\
\hline Percent foreign born & $17.85 \%$ & $1.15 \%$ & $38.17 \%$ & 0 \\
\hline \multicolumn{5}{|l|}{ Other } \\
\hline County population density & $2,817.92$ & 82.03 & $24,140.80$ & 0 \\
\hline Infant mortality rate & 66.934 & 33.722 & 110.00 & 0 \\
\hline Suffrage enacted before 1914 & $14.45 \%$ & 0 & 1 & 509 \\
\hline Suffrage enacted between 1915-1919 & $46.05 \%$ & 0 & 1 & 321 \\
\hline Suffrage enacted in 1920 & $39.50 \%$ & 0 & 1 & 360 \\
\hline
\end{tabular}

Notes:

1Source: Financial Statistics of Cities volumes, 1923-1932. All spending variables are in per capita terms and adjusted to 2007 dollars.

2Source: Manufacturing wages and the percent of manufacturing workers in heavy industry are obtained from the Census of Manufactures volumes, 1923-1933. The number of municipal tax returns are obtained from the Statistics of Income volumes published by the IRS, 1923-1932.

${ }^{3}$ Municipal demographics are from the Decennial Censuses and interpolated for the intercensal years

Table 2 - Basic Correlations

\begin{tabular}{lccc}
\hline Independent variable: TFR & $\begin{array}{c}\text { Public health } \\
\text { education }\end{array}$ & $\begin{array}{c}\text { Dependent variable } \\
\text { Charity for } \\
\text { children and }\end{array}$ & $\begin{array}{c}\text { Outdoor care } \\
\text { of poor }\end{array}$ \\
Coefficient & 0.0178915 & -0.0017744 & -0.001502 \\
& $(0.00762)$ & 0.00057 & $(0.00064)$ \\
Constant & 2.235 & 2.327 & 2.314 \\
& $(0.03052)$ & 0.01916 & $(0.01821)$ \\
\hline R squared & 0.009 & 0.0159 & 0.0091 \\
Obs & 595 & 595 & 595 \\
\hline
\end{tabular}


Municipal health and welfare spending ${ }^{a}$

Public health education

$-0.02347190^{\star *}$

$-\$ 42.6041$

Charity for children and mothers

$(0.0081)$

0.000629

(0.0039)

Outdoor care of poor

$-0.00267716^{\star}$

(0.0013)

Infant mortality rate

$0.00256204^{\star \star \star}$

(0.0007)

Women's suffrage ("Before 1914" omitted)

1915-1919

0.02263

(0.0198)

1920

0.01483

(0.0184)

Other spending variables ${ }^{a}$

Other health spending

$-0.00928213^{\star \star}$

(0.0030)

Sanitation spending

0.001419

(0.0013)

Other charitable spending

$-0.000437$

(0.0019)

Hospital spending

0.001206

(0.0024)

Spending on schools and libraries

$0.00151783^{\star *}$

(0.0005)

$\$ 1,589.0167$

$-\$ 373.5302$

$0.00002025^{\star \star}$

(0.0000)

\# of tax returns filed per capita

$1.18020623^{\text {** }}$

(0.4044)

City demographics ${ }^{\mathrm{a}}$

Proportion of workers in polluting industries

$0.27226127^{*}$

(0.1315)

Percent black

0.319971

(0.7213)

Percent illiterate

$-2.157171$

(2.0360)

County population density

$-0.00002921^{\star *}$

(0.0000)

Percent foreign born

$5.51736277^{\star \star *}$

(1.2782)

Constant

$0.80647416^{\star \star *}$

$(0.2377)$

City fixed effects

Year fixed effects

Y

$-\$ 2,290.0589$

$\$ 658.8353$

$\$ 49,382.7160$

Observations

541

Adjusted R-squared

Standard errors clustered at the Census region are in parantheses

* significant at $10 \%$; ${ }^{* *}$ significant at $5 \%$; ${ }^{* *}$ significant at $1 \%$

$\mathrm{TFR}^{*}$ is an estimated version of the Total Fertility Rate using state level age-specific fertility rates.

aAll variables in this category are set at one year lags. Government expenditures are per capita and adjusted to 2007 dollars 
Table 4 - Sensitivity Analyses

Dependent variable:

Municipal health and welfare spending a

Public health education

Charity for children and mothers

Outdoor care of poor

Logged outdoor care of poor

Infant mortality rate ${ }^{a}$

Women's suffrage ("Before 1914" omitted)

1915-1919

1920

Other spending variables ${ }^{a}$

Other health spending

Sanitation spending

Other charitable spending

Hospital spending

Spending on schools and libraries

City income variables ${ }^{a}$

Manufacturing wages per worker

\# of tax returns filed per capita

City demographics ${ }^{\mathrm{a}}$

Proportion of workers in polluting industries

Percent black

Percent illiterate

County population density

Percent foreign born

\begin{tabular}{|c|c|c|}
\hline Scaled GFR & $\begin{array}{c}\text { Omitting } 31 \\
\text { and } 32\end{array}$ & $\begin{array}{l}\text { Log transform } \\
\text { of outdoor }\end{array}$ \\
\hline (1) & (2) & (3) \\
\hline GFR & TFR* & TFR* \\
\hline$-0.0257^{\star \star}$ & -0.0135 & $-0.0204^{*}$ \\
\hline (0.0089) & (0.0098) & (0.0095) \\
\hline 0.0001 & 0.0047 & 0.0020 \\
\hline (0.0041) & $(0.0040)$ & (0.0037) \\
\hline \multirow{3}{*}{$\begin{array}{c}-0.00305^{*} \\
(0.0014)\end{array}$} & $-0.0113^{\star \star \star}$ & \\
\hline & $(0.0029)$ & \\
\hline & & $\begin{array}{l}-0.0189 * \star \star \\
(0.0053)\end{array}$ \\
\hline $\begin{array}{l}0.0026^{\star \star} \\
(0.0008)\end{array}$ & $\begin{array}{l}0.00192^{\star *} \\
(0.0006)\end{array}$ & $\begin{array}{c}0.00279^{* * *} \\
(0.0008)\end{array}$ \\
\hline 0.0224 & 0.0495 & 0.0190 \\
\hline$(0.0211)$ & $(0.0285)$ & $(0.0176)$ \\
\hline 0.0136 & 0.0390 & 0.0121 \\
\hline (0.0191) & $(0.0271)$ & $(0.0177)$ \\
\hline$-0.0089 \star *$ & $-0.0105^{\star \star}$ & $-0.01078^{\star \star}$ \\
\hline (0.0031) & (0.0038) & (0.0029) \\
\hline 0.0014 & 0.0022 & 0.0004 \\
\hline (0.0014) & $(0.0017)$ & $(0.0012)$ \\
\hline 0.0001 & $0.0067^{* *}$ & $-0.0046^{\star *}$ \\
\hline (0.0019) & $(0.0023)$ & (0.0019) \\
\hline 0.0019 & $-0.006196^{\star * *}$ & -0.0012 \\
\hline (0.0025) & $(0.0016)$ & $(0.0024)$ \\
\hline $0.00156^{\star \star}$ & $0.00092^{*}$ & $0.0019 * \star \star$ \\
\hline (0.0005) & (0.0004) & (0.0005) \\
\hline $0.000021^{* *}$ & $0.000018^{*}$ & $0.00002^{\star *}$ \\
\hline$(0.0000)$ & $(0.0000)$ & $(0.0000)$ \\
\hline $1.3853^{\star \star \star}$ & 0.0984 & $1.5772^{\star \star *}$ \\
\hline$(0.4049)$ & $(0.3503)$ & $(0.3393)$ \\
\hline $0.2832^{\star}$ & $0.569 * \star *$ & 0.1558 \\
\hline$(0.1472)$ & $(0.0657)$ & $(0.1542)$ \\
\hline-0.0989 & 2.7519 & 0.4427 \\
\hline$(0.7398)$ & $(2.2304)$ & $(0.7227)$ \\
\hline-0.3321 & $-7.9179 * *$ & -0.5882 \\
\hline (1.9990) & (2.8939) & (1.9595) \\
\hline$-0.000028^{*}$ & $-0.000043^{* * *}$ & $-0.000026^{\star \star}$ \\
\hline (0.0000) & $(0.0000)$ & $(0.0000)$ \\
\hline $5.941^{\star \star \star}$ & $8.5755^{\star \star}$ & $6.0113^{\star * *}$ \\
\hline (1.2488) & (2.6423) & $(1.2206)$ \\
\hline $\begin{array}{l}0.7657^{\star \star} \\
(0.2341)\end{array}$ & $\begin{array}{c}0.5456 \\
(0.4440)\end{array}$ & $\begin{array}{c}0.57189 \star \star \\
(0.2080)\end{array}$ \\
\hline
\end{tabular}

Constant

(0.2341)

City fixed effects

Year fixed effects

\begin{tabular}{lccc}
\hline Observations & 541 & 413 & 517 \\
Adjusted R-squared & 0.9259 & 0.9328 & 0.9277 \\
\hline \hline
\end{tabular}

Standard errors clustered at the Census region are in parantheses

* significant at $10 \%$; ** significant at $5 \%$; *** significant at $1 \%$

$\mathrm{TFR}^{\star}$ is an estimated version of the Total Fertility Rate using state level age-specific fertility rates.

${ }^{a}$ All variables in this category are set at one year lags. Government expenditures are per capita and adjusted to 2007 dollars 